\title{
BMJ Open Physical activity on prescription schemes (PARS): do programme characteristics influence effectiveness? Results of a systematic review and meta-analyses
}

\author{
Jelena Arsenijevic, ${ }^{1}$ Wim Groot ${ }^{1,2}$
}

To cite: Arsenijevic J, Groot W. Physical activity on prescription schemes (PARS): do programme characteristics influence effectiveness? Results of a systematic review and meta-analyses. BMJ Open 2017;7:e012156. doi:10.1136/bmjopen-2016012156

- Prepublication history and additional material is available. To view please visit the journal (http://dx.doi.org/ 10.1136/bmjopen-2016012156).

Received 4 April 2016 Revised 19 October 2016 Accepted 10 November 2016

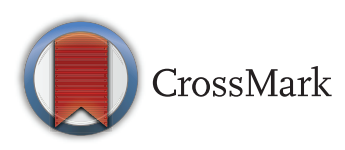

${ }^{1}$ Department of Health Services Research, CAPHRI, Maastricht University Medical Center, Faculty of Health, Medicine and Life Sciences, Maastricht University, Maastricht, The Netherlands ${ }^{2}$ Top Institute Evidence-Based Education Research (TIER), Maastricht University, Maastricht, The Netherlands

Correspondence to Dr Jelena Arsenijevic; j.arsenijevic@ maastrichtuniversity.nl

\section{ABSTRACT}

Background: Physical activity on prescription schemes (PARS) are health promotion programmes that have been implemented in various countries. The aim of this study was to outline the differences in the design of PARS in different countries. This study also explored the differences in the adherence rate to PARS and the self-reported level of physical activity between PARS users in different countries.

Method: A systematic literature review and metaanalyses were conducted. We searched PubMed and EBASCO in July 2015 and updated our search in September 2015. Studies that reported adherence to the programme and self-reported level of physical activity, published in the English language in a peerreviewed journal since 2000 , were included. The difference in the pooled adherence rate after finishing the PARS programme and the adherence rate before or during the PARS programme was $17 \%(95 \% \mathrm{Cl}$ $9 \%$ to $24 \%$ ). The difference in the pooled physical activity was 0.93 unit score $(95 \mathrm{Cl}-3.57$ to 1.71$)$. For the adherence rate, a meta-regression was conducted.

Results: In total, 37 studies conducted in 11 different countries met the inclusion criteria. Among them, 31 reported the adherence rate, while the level of physical activity was reported in 17 studies. Results from meta-analyses show that PARS had an effect on the adherence rate of physical activity, while the results from the meta-regressions show that programme characteristics such as type of chronic disease and the follow-up period influenced the adherence rate.

Conclusions: The effects of PARS on adherence and self-reported physical activity were influenced by programme characteristics and also by the design of the study. Future studies on the effectiveness of PARS should use a prospective longitudinal design and combine quantitative and qualitative data. Furthermore, future evaluation studies should distinguish between evaluating the adherence rate and the self-reported physical activity among participants with different chronic diseases.

\section{Strengths and limitations of this study}

- This the first study that examines the differences in programme characteristics related to physical activity on prescription schemes (PARS) in different countries. The effectiveness of PARS in different countries is examined using metaanalyses and meta-regression.

- To examine the effectiveness of PARS, we used two effect size measures: the adherence rate and the self-reported level of physical activity.

- To assess the effectiveness of PARS, this study also applied meta-regression that included programme characteristics as covariates.

- The selection of abstracts included only English language studies. There are evidence that some studies exist in the Dutch and Swedish languages also.

- It was impossible to perform a meta-regression on the self-reported level of physical activity.

\section{INTRODUCTION}

Physical activity on prescription schemes (PARS) are health promotion programmes delivered through primary healthcare institutions with the aim to increase physical activity among at-risk population groups. ${ }^{1-4}$ In a nutshell, within the PARS programme the health professional (general practitioner (GP) or nurse) gives a prescription to the eligible person. ${ }^{15}$ With this prescription, the person is referred to an exercise professional (physiotherapist) who organises a physical activity programme. Eligible people include those with metabolic disorders such as obesity, overweight, high cholesterol, a diagnosis of cardiovascular diseases, mental health problems, orthopaedic problems, sometimes also respiratory diseases and some types of cancer. $^{1}{ }^{6}$ The programme is 
sometimes free of charge but sometimes some payment is required as well, depending on the country where the programme is delivered. ${ }^{1} 78$ It is usually offered at a local community leisure facility and is provided by a physiotherapist or health professional. The goal of the programme is to provide a tailor-made easy accessible scheme of physical activity that suits the person and her/his medical needs. ${ }^{9}$ In this way, people with similar needs receive professional help in exercising and also a chance to perform the activities and share experiences with people who have similar needs.

In Europe, PARS programmes were first introduced in the UK during the 1990s. ${ }^{9}$ In 2002/2003, Sweden, Denmark, Norway and Finland introduced similar schemes $^{7} 1011$ and later on Netherlands, Germany (as a part of the 'healthy' Germany programme), ${ }^{8} 12$ Belgium, ${ }^{13}$ Spain and Portugal ${ }^{14}$ did the same. Outside Europe, PARS programmes exist in the USA, Canada, New Zealand and Australia. ${ }^{15-17}$ However, the name of the PARS programme, design and implementation vary between countries but sometimes also within a country.

The UK programme is known as PARS but also as exercise on prescription, while in Sweden the programme is usually referred to as physical activity on prescription (PAP).$^{10}$ Other synonyms include exercise on referral scheme (ERS), exercise is medicine or green prescriptions. ${ }^{18}$ In some countries, the programme is known as ERS (applied in the UK and Denmark) whereas in some other countries it is known as PARS (applied in Sweden, Finland and New Zealand). ${ }^{5} 19$ Nevertheless, nowadays, researchers use these terms interchangeably. ${ }^{1} 2021$

Regarding the design of PARS, differences are also observed between countries and also within a country. For example, the UK PARS programmes were developed at a national level, following the recommendation of the National Institute for Health and Clinical Excellence (NICE). NICE defined the requirements or general standards for PARS but each local community is allowed to develop its own unique programme. In 1994, the number of different registered PARS in the UK was 200, while in 2001 the number was three times higher. ${ }^{2}$ They differ in the targeting of eligible groups, reasons for referral, type of physical activities that are provided and also in the way in which the programme is evaluated. ${ }^{22}$ In some cases, PARS programmes are accompanied by motivational training for participants. ${ }^{6}$ Differences are also observed between countries. For example, in some countries, like in Spain, the programme is delivered free of cost, while in other countries patients pay a fee. ${ }^{23} \mathrm{In}$ the Netherlands, the programme is targeting people with health-related risk factors, such as obesity and diabetes, as well as those with low social economic status, whereas in Sweden only people with certain health risk factors are eligible. ${ }^{19}$

However, differences between countries have been examined only to a limited extent. Previous literature reviews have compared programmes in different countries, mostly in English-speaking countries. ${ }^{20}$ Programmes from non-English countries such as the Netherlands or Sweden have not been included. ${ }^{20} 24$ Evaluation studies, designed as randomised controlled trials (RCTs), prospective longitudinal studies or cohort studies $^{6} 22 \quad 2526$ focus on the effectiveness of PARS within the same country or even within the same local communities where they have been implemented. ${ }^{6} 2728$ Those studies also identify three main obstacles related to the effectiveness of PARS, namely a lack of theoretical background for the intervention, low adherence rate among the participants in PARS and unclear evidence regarding the effectiveness of PARS on physical activity. 1629

Following the obstacles acknowledged by previous studies, the aim of this study was to outline the differences in design and effectiveness of PARS programmes in different countries. We particularly focused on the adherence rate and the self-reported level of physical activity. Those two dimensions have been used as measures of effectiveness in previous studies. ${ }^{25} \quad 30$ Furthermore, we compared the design of PARS programmes in different countries. Comparing the design of PARS programmes from different countries can give better insight into how to improve the adherence rate among participants and how to increase the long-term effectiveness of PARS. For this purpose, we performed a systematic literature review and a meta-analysis. We use meta-analysis in order to assimilate the data from different sources and from different countries. ${ }^{31}$

\section{BACKGROUND}

In 1978, the American College of Sports Medicine recommended that adults older than 18 years should be engaged in moderate physical activity at least $30 \mathrm{~min}$ per day. ${ }^{28}$ Following this recommendation, the British NICE and National Health Service (NHS) initiated health promotion interventions that aimed to increase the level of physical activity by facilitating access to leisure community centres. ${ }^{3}$ Such activities include community-based programmes for walking and cycling, pedometers and exercise on referral schemes. ${ }^{32}$ As mentioned in the 'Introduction' section, similar schemes have been developed in Sweden, Denmark, Finland and the Netherlands based on the same motivation, namely to increase physical activity among adults with a sedentary lifestyle. ${ }^{7334}$ Contrary to the guidelines for developing health promotion interventions, PARS were not developed based on a particular theoretical background but rather on policy recommendations. ${ }^{30}$ This is one of the reasons that the design, implementation and evaluation differ between countries. Despite those differences, the previous literature has suggested several phases that describe the process of PARS. ${ }^{1}{ }^{2}$ We present them in table 1 .

In this study, we focus on the first phase-the design of the PARS programme and on some characteristics 
Table 1 Description of the PARS

Phase I: getting the referral

Phase II: the implementation of the programme

Phase III: financial planning

Phase IV: possible obstacles to programme sustainability

Who is eligible to get the referral within PARS? Who can give the referral? What kind of physical activity can be prescribed? Evaluation measures Who will deliver the programme? Where will the programme be delivered? What is the duration of the programme?

How is it funded? Who pays for the programme? What are the patients costs? What are the financial incentives for providers?

Indirect patient costs (transport, equipment). Psychological obstacles (low self-confidence, etc). Organisational obstacles (facilities or programme was not patient-centred). Communication between patients and providers.

Phase V: effectiveness Comparing the level of physical activity before and after the programme started. Comparing the adherence rate during the programme and after the programme is finished. Comparing the level of mental health before and after the programme. Comparing the clinical outcomes before and after the programme.

Source: Dugdill L, Graham RC, McNair F. Exercise referral: the public health panacea for physical activity promotion? A critical perspective of exercise referral schemes; their development and evaluation. Ergonomics 2005;48(11-14):1390-410.

PARS, physical activity on prescription schemes.

related to phases II and III. In particular, we focus on the following characteristics: reasons for referral, who can prescribe PARS, what kind of physical activity can be prescribed, the duration of the programme and patient payments. We also examine the adherence rate and selfreported level of physical activity, related to phase V.

\section{METHOD}

We conducted this review in accordance with the Preferred Reporting Items for Systematic Reviews and Meta-Analyses (PRISMA) strategy.

\section{Inclusion and exclusion criteria}

We included studies that meet the following criteria:

- Studies with the following designs-RCT, prospective longitudinal studies, cohort studies, mixed design and qualitative studies that examine PARS.

- Studies that use as a population group adults older than 18 years.

- Studies published in peer-reviewed journals in the English language after 2000.

- Studies that report one of the following outcome measures: adherence rate and self-reported physical activity level.

We excluded studies that use PARS participants to check new theoretical approaches or check psychometric characteristics of instruments. ${ }^{36}$ We also excluded studies that are literature reviews. Also, we excluded studies that use data from other studies to model costeffectiveness and studies that have been published as a report, opinion papers or national guideline. We also excluded studies that examine PARS characteristics from the physician's perspective. Furthermore, we excluded studies that just describe the design of the RCT related to PARS before those RCTs are conducted.

\section{Searching strategy, study selection and data extraction}

Relevant studies were collected using PubMed and EBESCO. For the identification of key words, we followed the strategy proposed by Pavey et al..$^{25}$ The strategy is based on a scope research to identify relevant synonyms for PARS and then the synonyms were combined with the term primary care. We performed the literature search within both databases using the following chain of key words (the same chain is used in Pavey et $\left.a l^{25}\right)$ : "( ( ( exercise on referral) OR physical activity on prescription) OR exercise on prescription) AND primary care".

An initial search within PubMed identified 669 studies. Applying filters for year of publication, population characteristics and language of publication, 556 studies were included. After checking the titles and abstracts, 69 studies that address PARS were identified. Among them, 8 were excluded as opinion papers, ${ }^{37-44} 4$ as literature review, ${ }^{4} 2545464$ were excluded because they only reported on the design of RCT studies (protocol), ${ }^{15} 2847-493$ were excluded as reports, ${ }^{9} 5051$ and 8 were excluded because they examined the physician's opinion about PARS. ${ }^{52-59}$ After checking for the last inclusion criteria, nine were excluded. $^{3} 2427$ 60-64 Through PubMed we identified 27

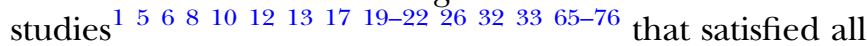
inclusion criteria and were in accordance with the exclusion criteria. We also performed a search using EBASCO (it includes also SocINDEX), and we identified 99 studies. Among them, 14 studies met the inclusion criteria. However, those studies were already identified via PubMed.

Besides the chain proposed by Pavey et $a l,{ }^{9}{ }^{25}$ we also performed a search using the chain of key words that incorporated all synonyms that we identified and that were related to PARS.

" $((((($ exercise on referral) OR physical activity on prescription) OR exercise on prescription) OR medicine is exercise) OR green prescription) AND health promotion) AND primary care".

We also searched the databases PubMed and EBASCO using the second chain of key words that incorporate all synonyms that we have identified and that are related to 
PARS. Again, we were able to identify only 27 studies. After the initial selection of studies, we also checked their reference lists for additional literature. A publication from the reference list (bibliography) is included in the review after applying the same inclusion and exclusion criteria. Furthermore, we also did a forward-search by finding the authors who cite the included papers. For this purpose, we used Google Scholar. Also, we used literature review studies to check whether we include studies that have been identified in previous literature reviews. We did this in order to decrease publication bias. ${ }^{25}$

Through this additional search, we identified 10 additional studies that met our inclusion criteria. $\begin{array}{lllllllll}7 & 11 & 14 & 18 & 23 & 37-80 & \text { In total, we included } 37\end{array}$ studies (see figure 1). The full strategy for PubMed is available in online supplementary files (see PubMed_searching_strategy).

\section{DATA EXTRACTION AND ANALYSES}

Because we included studies with different designs, heterogeneous sample types and size and different outcome measures, we first extracted the data related to the characteristics of the included studies. ${ }^{31}$ Those were aims of the studies, designs of the studies, sample characteristics, response rates, follow-up periods, methods of data collection within the studies, primary and secondary outcome measures, and analyses applied, reported adherence rates and reported levels of physical activity. Those data are presented in detail in online supplementary appendix 1 . We also used summary statistics to present some of those characteristics (see the 'Results' section, table 2).

Data related to the design of PARS programmes include reasons for referral (such as sedentary behaviours or type of chronic disease), who can prescribe PARS (GP or other health professionals), where PARS is conducted (in a community leisure facility or at home), duration of the programme (number of weeks), type of physical activity that is applied (aerobics, swimming, walking, etc), participants costs and country where the programme is conducted were also extracted. ${ }^{22}$ Those data are also presented in the 'Results' section (table 3).

We also reported adherence rate and self-reported level of physical activity as measures of effectiveness. Adherence is defined as the patient's active choice to follow the medical recommendation instead of passive compliance. Adherence level is reported in almost all studies as the proportion of people who adhere to more than $80 \%$ of all PARS activities. After the PARS has ended, the adherence rate is measured as the

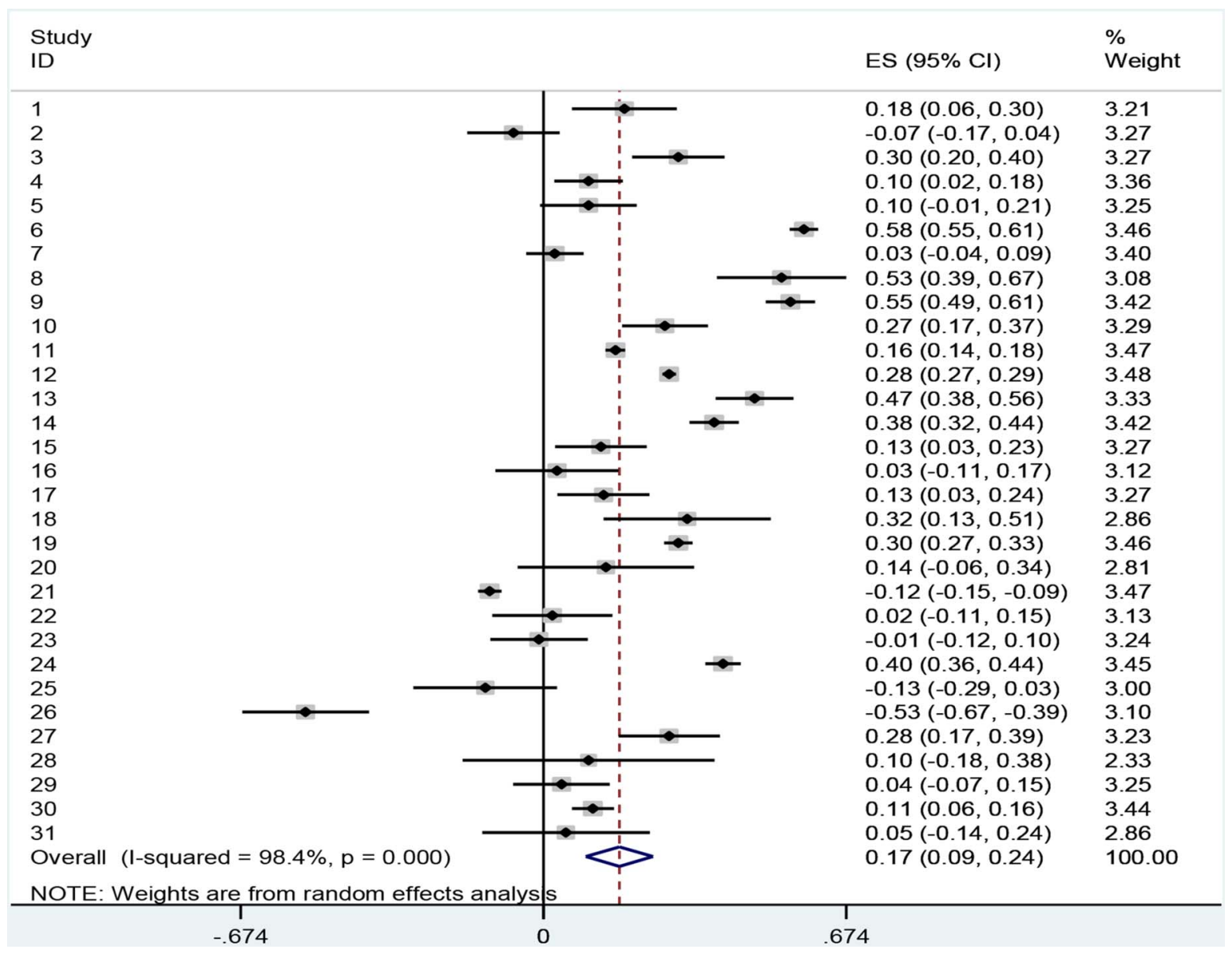

Figure 1 Meta-analyses of adherence rate level among PARS participants. PARS, physical activity on prescription schemes. 


\begin{tabular}{|c|c|c|c|c|c|c|}
\hline & Reason for referral & $\begin{array}{l}\text { Who can } \\
\text { prescribe }\end{array}$ & $\begin{array}{l}\text { Where is } \\
\text { taken }\end{array}$ & $\begin{array}{l}\text { Type of } \\
\text { physical activity }\end{array}$ & $\begin{array}{l}\text { Participants } \\
\text { payments }\end{array}$ & $\begin{array}{l}\text { Duration of the } \\
\text { programme }\end{array}$ \\
\hline UK & $\begin{array}{l}\text { Cardiovascular diseases }{ }^{\star}(3,4,5,12,13,14 \text {, } \\
15,16,22,28,36,37) \\
\text { Diabetes mellitus }(3,4,13,14,16,36,37) \\
\text { Sedentary behaviour }(3,4,13,16,22) \\
\text { Asthma }(3,4,28,37) \\
\text { Overweight/obese }(4,13,14,16,36,37) \\
\text { Depression }(3,4,5,16) \\
\text { Osteoporosis }(4,13,28,37)\end{array}$ & $\begin{array}{l}\text { GP } \\
\text { Nurse } \\
\text { Other healthcare } \\
\text { professional }\end{array}$ & $\begin{array}{l}\text { Facility } \\
\text { based }\end{array}$ & $\begin{array}{l}\text { Aerobics } \\
\text { Swimming } \\
\text { Walking }\end{array}$ & $\begin{array}{l}\text { Yes, reduced } \\
\text { price }\end{array}$ & $\begin{array}{l}8-10(16,36) \\
12-14 \text { weeks } \\
(3,4,13,14) \\
16 \text { weeks } \\
\text { Up to } 26(37)\end{array}$ \\
\hline Sweden & $\begin{array}{l}\text { Cardiovascular diseases } \\
(24,26,31,17,18,19) \\
\text { Diabetes mellitus } \\
(17,18,19,24,25,26,31) \\
\text { Sedentary behaviour }(24,26) \\
\text { Asthma }(24,26) \\
\text { Overweight/obese }(17,18,19,25,26,31)\end{array}$ & $\begin{array}{l}\text { GP } \\
\text { Other health } \\
\text { professionals }\end{array}$ & $\begin{array}{l}\text { Facility } \\
\text { based=0 } \\
\text { Home } \\
\text { based=0 } \\
\text { Both=all } \\
\text { articles }\end{array}$ & $\begin{array}{l}\text { Nordic walking } \\
\text { Swimming } \\
\text { Gardening }\end{array}$ & Yes & No data \\
\hline NL & $\begin{array}{l}\text { Minorities }(7,32) \\
\text { People from low social economic status } \\
(7,32)\end{array}$ & GP & $\begin{array}{l}\text { Facility } \\
\text { based }\end{array}$ & Aerobics & Yes & 18 weeks \\
\hline Denmark & $\begin{array}{l}\text { Sedentary lifestyle } \\
\text { Chronic diseases }\end{array}$ & GP & $\begin{array}{l}\text { Facility } \\
\text { based }\end{array}$ & $\begin{array}{l}\text { Aerobics } \\
\text { Walking }\end{array}$ & Yes, full price & 4 months \\
\hline Spain & Chronic diseases $(10,11)$ & GP & $\begin{array}{l}\text { Facility } \\
\text { based }\end{array}$ & Walking & No & 6 months \\
\hline Canada & $\begin{array}{l}\text { Older adults ( } 21) \\
\text { Women with sedentary behaviour (8) }\end{array}$ & GP & $\begin{array}{l}\text { Facility } \\
\text { based }\end{array}$ & Aerobics & No & 8 weeks \\
\hline $\begin{array}{l}\text { Australia/New } \\
\text { Zealand }\end{array}$ & $\begin{array}{l}\text { Women with sedentary lifestyle (23) } \\
\text { Patients with cancer (27) }\end{array}$ & $\begin{array}{l}\text { GP and other health } \\
\text { professionals }\end{array}$ & Both & Aerobics & Yes & 12 weeks \\
\hline USA & $\begin{array}{l}\text { Sedentary lifestyle in older adults( } 1,29) \\
\text { Different chronic diseases (33) }\end{array}$ & GP & Both & Aerobics & Yes & 24 weeks \\
\hline
\end{tabular}

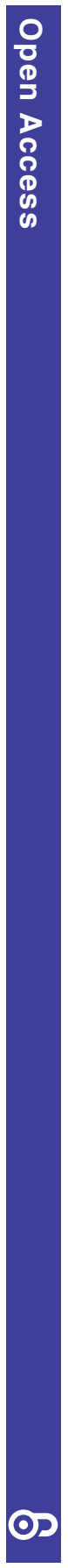

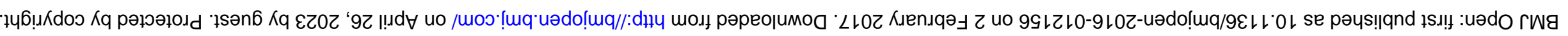


between the proportion of those who adhere (continue) with physical activity after finishing the PARS programme and the level of physical activity before the PARS programme. If information on physical activity before the programme was not available, we used information on the level of activity during the programme. In case the standardised difference is positive, we conclude that PARS had a positive effect on adherence. Additionally, we performed a meta-analysis including only the studies with a randomised clinical trial and compared the adherence rate of the intervention group with the adherence rate of the control group (see online supplementary appendix 2).

The second effect size measure was the standardised difference between the means in the level of the selfreported physical activity score at the beginning of PARS and after a certain follow-up period. This effect size measure is known as Cohen's d, and it is calculated based on the equation reported in other studies. ${ }^{31}$ In case the SD or mean was not reported, we calculated it from the CI. Also, when mean and SDs were reported for different subpopulation groups within the same study, we summarised results across all groups in accordance with reported standards. ${ }^{83}$ We analysed the data using a random-effect meta-analyses approach. ${ }^{31}$ By using a random-effect model, we took into account between and within study variance. For each effect size measure, we ran separate meta-analyses using the METAN command in STATA (Harris R, Bradburn M, Deeks J, et al. METAN: Stata module for fixed and random effects meta-analysis. Statistical Software Components 2010).

After the meta-analyses, we also performed meta-regression. We used each effect size measure as a dependent variable. As a covariate, we included a binary indicator whether the study originates from Australia, Canada, New Zealand, the USA or Europe. We used European countries as a reference category. Also, as a covariate, we included the follow-up period reported in the study. The follow-up period can influence the adherence rate: the adherence rate is lower with a longer follow-up period. ${ }^{25} 83$ We also included three binary indicators related to the main reasons for referral: sedentary lifestyle, having cardiovascular diseases, having diabetes and being overweight/obese. Previous studies have shown that the reason for referral can decrease the adherence rate among population groups such as overweight individuals. ${ }^{9}{ }^{25}$ It is also known that a longer duration of PARS programme can improve the level of physical activity among participants. At the same time, a longer duration is associated with a lower adherence rate. Therefore, we also included programme duration as a covariate. The study quality score was also included as a covariate, since the quality of the study can influence both measures of effectiveness. We used a random-effect meta-regression. Heterogeneity between the studies was measured through the $\mathrm{I}^{2}$ statistic (with a value higher than $75 \%$ considered as large). The proportion of between study variance explained by the model is calculated through $\operatorname{tau}^{2}$ (Harris R, Bradburn M, Deeks J, et al. METAN: Stata module for fixed and random effects meta-analysis. Statistical Software Components 2010). Those results are presented in the 'Results' section (table 4).

Because we included studies with different characteristics-different study designs, sample sizes and applied methods-publication bias might be expected. To assess publication bias related to self-reported levels of physical activity (the standardised differences of two means), we used the Eggers test. ${ }^{84}$ This test measures the funnel plot asymmetry using linear regression in which standardised effect size measures (effect size divided by its own $\mathrm{SE}$ ) is regressed against its precession (the inverse of effect size SE). If the intercept in this regression is significantly different from zero, this means that publication bias is present.

To assess publication bias related to the adherence rate as effect size (the difference between two proportions), we used the Begg and Mazumdar's rank correlation tests-a rank order correlation between the standardised effect size measure and its precession.

\section{RESULTS}

Table 2 presents the characteristics of the included studies. The majority of the studies originate from the

Table 4 Results from meta-regression using difference in proportion of adherence rate

\begin{tabular}{lcc}
\hline Independent predictors & Coefficient & SE \\
\hline Quality of the study & -0.385 & 0.375 \\
Duration of the programme & 0.005 & 0.007 \\
Follow-up period & $0.016^{* *}$ & 0.009 \\
Including people diagnosed with diabetes & $0.226^{* *}$ & 0.120 \\
Including people diagnosed with cardiovascular diseases & $-0.263^{*}$ & 0.119 \\
Including people diagnosed with obesity & 0.004 & 0.145 \\
Including people with sedentary lifestyle behaviour & 0.052 & 0.008 \\
Studies originating outside Europe & $-0.257^{*}$ & 0.014 \\
$I^{2}$ & $96.8 \%$ & 0.04 \\
Tau & &
\end{tabular}


UK-13 (35.2\%), while Canada, Denmark, Spain and the USA and are represented by $3(8.1 \%$ of total included) studies. RCT as a study design is used in 24 $(64.8 \%$ of the 37 included) studies. The average follow-up period in the included studies is 6 months. Only 16 (43.2\% of included studies) studies report measures related to physical activity while the adherence rate is reported in 30 ( $81.1 \%$ of included studies) studies.

Table 3 presents the results related to the programme design in different countries. The duration of the programme varies per country. In Sweden, there is no limitation on programme duration, while in the UK the duration of the programme is the shortest and ranges from 8 to 16 weeks, and in Spain it is the longest ranging until 6 months. In all countries, the main reason for referral is a chronic disease and sedentary lifestyle. In Canada, the USA and Sweden, the programme is delivered as a facility based and a home-based activity whereas in other countries it is exclusively a facility-based and supervised activity. GPs are most often the prescribers $(62 \%)$, although other health professionals are also included.

The results of the meta-analyses are presented in figures 1 and 2. The difference in the pooled adherence rate measured at the beginning of the PARS programme and the adherence rate measured after the PARS programme was $17 \%$ (95\% CI $9 \%$ to $24 \%$ ). The difference in the pooled physical activity measured by 7-day PAR at the beginning of PARS and after a certain follow-up period was 0.93 unit score (95 CI -3.57 to 1.71 ).

Table 4 presents the results of the meta-regression with the adherence rate as the dependent variable. The results show that the effectiveness of PARS on the adherence rate is associated with the duration of the treatment. Furthermore, studies that include participants diagnosed with a sedentary lifestyle and diabetes also report a higher adherence rate. Obesity and cardiovascular diseases are not associated with a higher adherence rate. Studies that come from Australia, Canada and the USA have a lower effectiveness in increasing the adherence rate than studies originating from Europe.

Figure 3 presents the results from risk bias Begg and Mazumdar's rank correlation tests. Tests show that there is no correlation between the standardised effect size measure (difference in proportion related to adherence rate) and its precession. In other words, a test shows that there is no publication bias effect for this effect size measure.

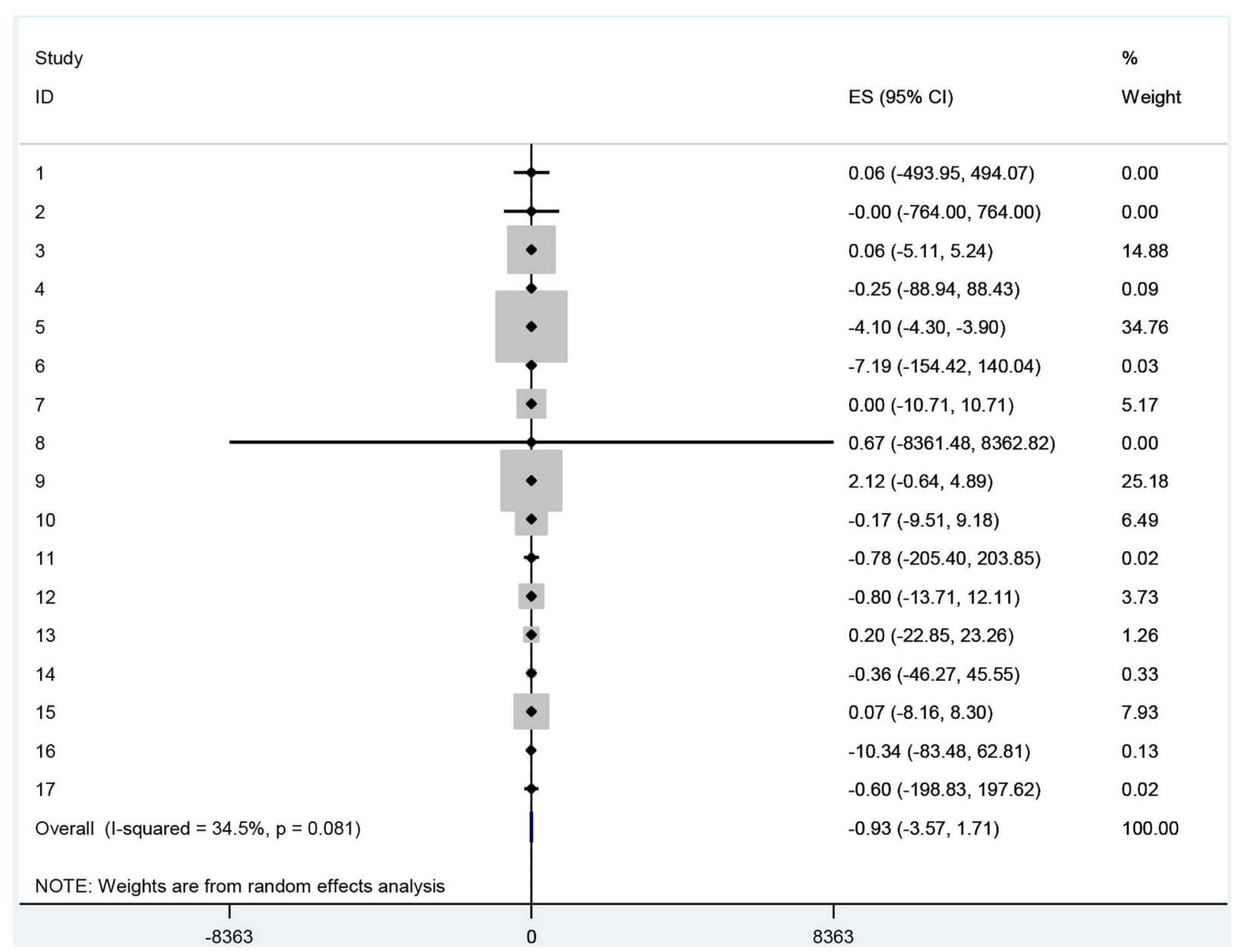

Figure 2 Meta-analyses of physical activity level among PARS participants. PARS, physical activity on prescription schemes. 
Figure 3 Funnel plot of effect size versus SE (random effects model).

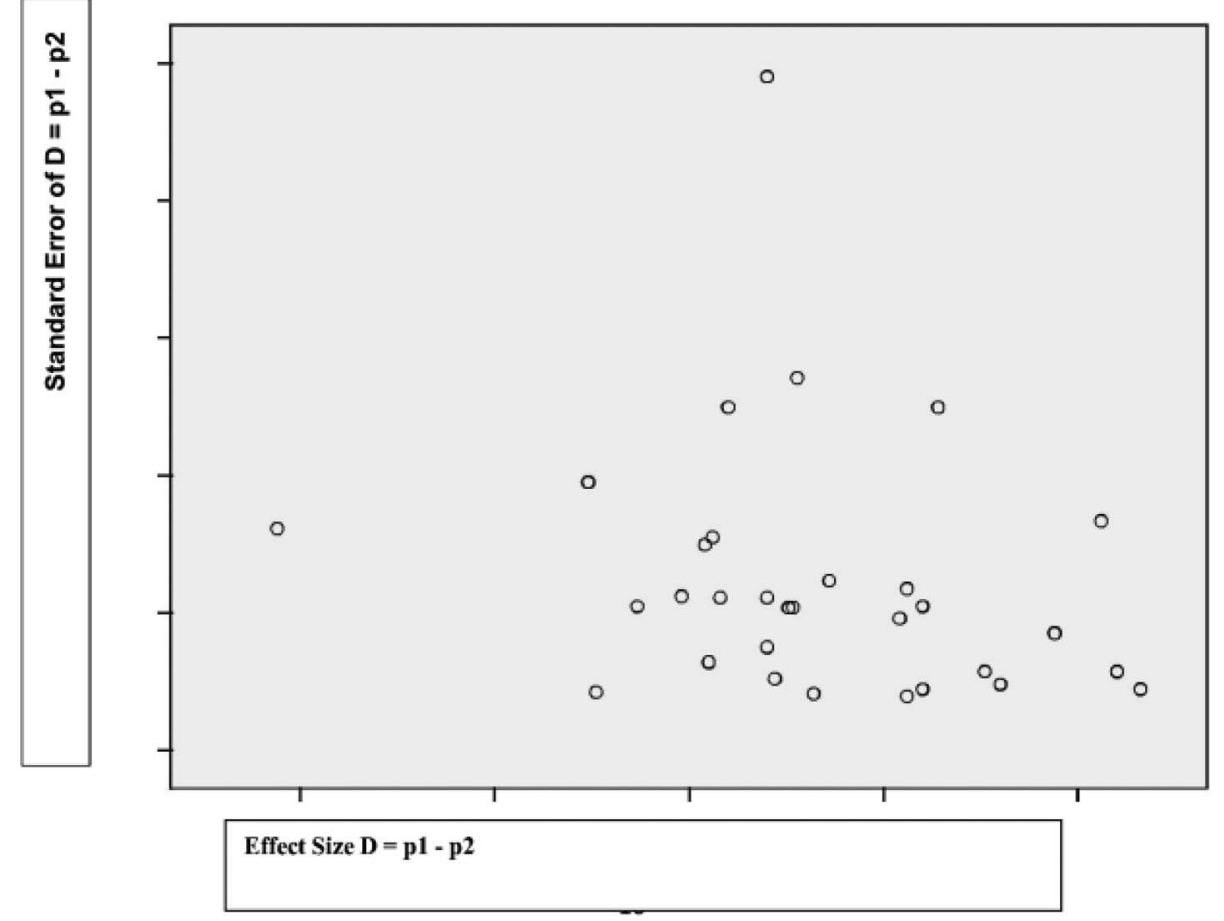

Table 5 presents the results from Eggers test. ${ }^{84}$ The results of the Egger test show that publication bias is present $(\mathrm{p}<0.06)$.

\section{DISCUSSION}

Our results from the literature review show that characteristics of the PARS programme are associated with self-reported levels of physical activity. For example, a longer duration of the PARS programme in some parts of the UK is associated with a higher level of selfreported physical activity (see online supplementary appendix 1). Studies included in this literature review show the large heterogeneity in design characteristics between countries. The main differences are related to the duration of the programme, reasons for referral and patient payments. One explanation for this can be the different positions that primary healthcare providers have within healthcare systems. It is also seen that PARS characteristics such as charges participants have to pay depend on the policy design of PARS. These differences are also observed within countries. One example is the duration of the programme: in the UK, it can take 8 but also 26 weeks. Those variations are related to the UK national policy that tries to embed PARS within the local

\begin{tabular}{lllll} 
Table 5 & Egger's test & & & \\
\hline & Coefficient & SE & \multicolumn{1}{l}{} & p Value \\
\hline Slope & -4.12 & 0.12 & -35.05 & 0.00 \\
Bias & 0.58 & 0.28 & 2.02 & 0.05 \\
\hline
\end{tabular}

community, and therefore each community can design its own interventions. Results from a previous literature review suggest that the effectiveness of PARS increases with the duration period. ${ }^{46}$ However, results related to meta-regression in this study show that the duration of the programme is not related to the adherence rate.

Another peculiarity of the design of PARS programmes is that in some countries, health status is not the only reason for referral but sociodemographic characteristics play a role as well. This is, for example, the case in the Netherlands where PARS is adapted to minorities and in Canada where particular attention is paid to women. Our results related to the literature review and different programme characteristics show that heterogeneity in the target groups for the PARS programme can lead to bias in the estimate of effectiveness. Publications that target particular groups with a unique reason for referral report greater effectiveness of PARS than publications that include heterogeneous groups of participants. Although PARS is intended to provide better access to physical leisure centres for certain population groups, small fees that are charged in some countries do not affect financial accessibility (see online supplementary appendix 1 and table 3 ). This is observed in the Netherlands, the UK and Sweden. In the Netherlands, PARS participants pay a small fee of $\sim 21$ euro, but if they participate in more than $80 \%$ of the meetings, they receive 10 euro back. In this way, small fees are used to increase the intrinsic motivation and consequently influence adherence among the participants. However, those observations are based on the literature review. The information regarding patient 
payments are not included in meta-regression. Furthermore, some studies from the literature review report that the lack of time is more important for the success of PARS than the participation fee. This is of particular importance for middle-aged adults and female participants. ${ }^{21} 2285$ One way to save the invested time is the implementation of the programme in a home-based environment such as walking programmes in Sweden. ${ }^{21}$

The importance of design characteristics for the effectiveness of PARS programmes is also confirmed in the meta-regression. We were able to apply meta-regression using the difference in the adherence rate as an outcome measure since only 17 publications report the level of physical activity at different points in time. Although the basic meta-analyses show positive effects of PARS on selfreported level of physical activity, those results are limited by the low number of included studies and the short follow-up period. Our results on the adherence rate show that a longer follow-up period is associated with greater effectiveness. From the perspective of participants, the follow-up period is seen as a continuation of the programme, since during this period they stay in touch with healthcare professionals and other participants. Furthermore, the reason for referral also plays a role in the effectiveness of PARS related to the adherence rate. While some reasons for referral like diabetes mellitus are positively associated with an increased adherence rate, others like being obese are not. This is of particular importance since obese people represent one of the main target groups for PARS. One of the explanations is that the lack of self-esteem among obese people is a barrier to participate in group activities.

Findings from this study are in accordance with previous studies. ${ }^{96}$ However, this study goes one step beyond that. It shows that the effectiveness of the PARS programme should be evaluated taking into account specific dimensions of design and implementation. For example, providing access to a physical leisure centre is important but not a sufficient step to increase physical activity. Even, with tailor-made programmes, targeting specific population groups such as women and older adults is just one step in providing a successful programme. Other steps include making a difference between diagnostic categories. Although the main purpose of the programme was to target people with a sedentary lifestyle and obesity, it seems that programmes delivered in community leisure centres are not effective for those groups. Results from Sweden where the programme is implemented in home surroundings and from the Netherlands where the programme addresses specific cultural needs of participants provide more successful stories than PARS programmes which include different population groups with different reasons for referral and different sociodemographic characteristics. ${ }^{12} 19$ Also, a distinction should be made in recommendations about PARS programmes for people diagnosed with certain diseases. For example, in this study, we include publications on the evaluation of PARS programmes among patients with cancer and stroke, although such programmes are rather rare. The evaluation of PARS programmes applied to those specific groups should be different from the evaluation of PARS programmes applied as a prevention strategy for a more general population.

Our results are bounded by certain limitations. One of the limitations of this study is that only one person was involved in the study selection and data extraction. The majority of the studies included in the literature review come from English-speaking countries with RCT as the dominant research design. An exception is Sweden, where the majority of the studies are based on a longitudinal prospective design. ${ }^{19} 2033$ RCT is the most prevalent study design reported in $65 \%$ of the publications included in this study. Although RCT is considered to be a 'golden standard' in the evaluation of health promotion interventions, it is frequently limited by a short-time follow-up period. In this study, the average reported follow-up is 6 months. Previous studies have already outlined that the effectiveness of health promotion programmes that aim to change participants' behaviour should be examined over a longer period of time. ${ }^{25}$ Quasi-experimental designs within RCT also prevent the examination of the effectiveness of PARS in real circumstances. ${ }^{22}$ Another limitation of this study is related to the reported outcome measures. We have focused in particular on the adherence rate and on self-reported physical activity. Adherence to the prescribed programme and the self-reported level of physical activity are complex and, to some extent, arbitrary concepts. Adherence to the prescribed programme is also related to information that the patient has about the programme, the perceived benefits from the programme, patient characteristics, social support and relation with the health professionals. ${ }^{87} 88$ The self-reported level of physical activity is also a subjective measure that depends on the participant's perception. ${ }^{45}$ Another limitation is related to high heterogeneity in effect size measures. When we used the adherence rate as an effect size measure, heterogeneity among the studies was high. In order to address this, we applied a random-effect model. Heterogeneity in effect size may have different causes. We explored whether this heterogeneity was related to the design of the study, the length of the follow-up period or the country where the study was conducted. We performed meta-analyses using only studies with a randomised design, studies with a programme duration longer than 12 weeks and studies using data from Europe. Only when the duration of the programme was longer than 12 weeks, heterogeneity was lower. On the basis of these results, it is likely that different factors cause heterogeneity in effect size. Furthermore, evaluation of health promotion programmes should also include cost-effectiveness measures. ${ }^{26}$ This was not possible since only studies from the UK report on the costeffectiveness of PARS, calculated from a societal perspective. 


\section{CONCLUSIONS}

For the future evaluation of PARS programmes, more objective measures that include longer follow-up periods should be included. Furthermore, the evaluation of the programme should be compared with programmes with similar designs taking into account the included target population and reasons for referral. Including information related to participants' direct and indirect costs (travel costs) should also improve the quality of the evaluation process.

For the PARS programme, targeting particular groups, taking into account their preferences and providing programmes during a longer period of time even with small participants fees, seems to lead to greater effectiveness of the programme than implementation within a general population group.

Contributors JA developed the study design, carried out the literature search and analysis, drafted and improved the manuscript, approved the final version and agreed to be accountable for her contribution. WG contributed to the development of the study design, reviewed the literature search and analysis, reviewed and commented on the preliminary drafts and final version of the paper, approved the final version and agreed to be accountable for his contribution.

Funding This paper arises from the project Pro-Health65+, which has received funding from the European Union, in the framework of the Health Programme (2008-2013).

Disclaimer The content of this paper represents the views of the author and it is his sole responsibility; it can in no way be taken to reflect the views of the European Commission and/or the Executive Agency for Health and Consumers or any other body of the European Union. The European Commission and/or the Executive Agency do(es) not accept responsibility for any use that may be made of the information it contains.

Competing interests None declared

Provenance and peer review Not commissioned; externally peer reviewed.

Data sharing statement Extra data are available by emailing: j. arsenijevic@maastrichtuniversity.nl

Open Access This is an Open Access article distributed in accordance with the Creative Commons Attribution Non Commercial (CC BY-NC 4.0) license, which permits others to distribute, remix, adapt, build upon this work noncommercially, and license their derivative works on different terms, provided the original work is properly cited and the use is non-commercial. See: http:// creativecommons.org/licenses/by-nc/4.0/

\section{REFERENCES}

1. Dugdill L, Graham RC, McNair F. Exercise referral: the public health panacea for physical activity promotion? A critical perspective of exercise referral schemes; their development and evaluation. Ergonomics 2005;48:1390-410.

2. Gidlow C, Johnston LH, Crone D, et al. Attendance of exercise referral schemes in the UK: a systematic review. Health Educ J 2005;64:168-86.

3. Moore GF, Moore L, Murphy S. Facilitating adherence to physical activity: exercise professionals' experiences of the National Exercise Referral Scheme in Wales: a qualitative study. BMC Public Health 2011;11:935.

4. Williams $\mathrm{NH}$, Hendry $\mathrm{M}$, France $\mathrm{B}$, et al. Effectiveness of exercise-referral schemes to promote physical activity in adults: systematic review. Br J Gen Pract 2007;57:979-86.

5. Murphy SM, Edwards RT, Williams N, et al. An evaluation of the effectiveness and cost effectiveness of the National Exercise Referral Scheme in Wales, UK: a randomised controlled trial of a public health policy initiative. J Epidemiol Community Health 2012;66:745-53.
6. Duda JL, Williams GC, Ntoumanis N, et al. Effects of a standard provision versus an autonomy supportive exercise referral programme on physical activity, quality of life and well-being indicators: a cluster randomised controlled trial. Int J Behav Nutr Phys Act 2014;11:1.

7. Sørensen J, Sørensen JB, Skovgaard T, et al. Exercise on prescription: changes in physical activity and health-related quality of life in five Danish programmes. Eur J Public Health 2011;21:56-62.

8. Gabrys L, Michallik L, Thiel C, et al. Effects of a structured physical-activity counseling and referral scheme in long-term unemployed individuals: a pilot accelerometer study. Behav Med 2013;39:44-50.

9. Pavey TG, Anokye N, Taylor $\mathrm{AH}$, et al. The clinical effectiveness and cost-effectiveness of exercise referral schemes: a systematic review and economic evaluation. Health Technol Assess 2011;15:i-xii, $1-254$.

10. Romé Å, Persson U, Ekdahl C, et al. Physical activity on prescription (PAP): costs and consequences of a randomized, controlled trial in primary healthcare. Scand J Prim Health Care 2009;27:216-22.

11. Karjalainen JJ, Kiviniemi AM, Hautala AJ, et al. Effects of exercise prescription on daily physical activity and maximal exercise capacity in coronary artery disease patients with and without type 2 diabetes. Clin Physiol Funct Imaging 2012;32:445-54.

12. Gademan MG, Deutekom M, Hosper K, et al. The effect of exercise on prescription on physical activity and wellbeing in a multi-ethnic female population: a controlled trial. BMC Public Health 2012;12:1

13. Hansen D, Peeters S, Zwaenepoel B, et al. Exercise assessment and prescription in patients with type 2 diabetes in the private and home care setting: clinical recommendations from AXXON (Belgian Physical Therapy Association). Phys Ther 2013;93:597-610.

14. Gusi N, Reyes MC, Gonzalez-Guerrero JL, et al. Cost-utility of a walking programme for moderately depressed, obese, or overweight elderly women in primary care: a randomised controlled trial. BMC Public Health 2008;8:231.

15. Knight E, Petrella RJ. Prescribing physical activity for healthy aging: longitudinal follow-up and mixed method analysis of a primary care intervention. Physician Sportsmed 2014;42:30-8.

16. Fortier MS, Hogg W, O'Sullivan TL, et al. The physical activity counselling (PAC) randomized controlled trial: rationale, methods, and interventions. Appl Physiol Nutr Metab 2007;32:1170-85.

17. Lawton BA, Rose SB, Elley CR, et al. Exercise on prescription for women aged 40-74 recruited through primary care: two year randomised controlled trial. BMJ 2008;337:a2509.

18. Pfeiffer BA, Clay SW, Conatser RR. A green prescription study does written exercise prescribed by a physician result in increased physical activity among older adults? J Aging Health 2001;13:527-38.

19. Kallings LV, Leijon M, Hellénius ML, et al. Physical activity on prescription in primary health care: a follow-up of physical activity level and quality of life. Scand J Med Sci Sports 2008;18:154-61.

20. Leijon ME, Bendtsen $\mathrm{P}$, Nilsen $\mathrm{P}$, et al. Does a physical activity referral scheme improve the physical activity among routine primary health care patients? Scand J Med Sci Sports 2009;19: 627-36.

21. Leijon ME, Faskunger J, Bendtsen $\mathrm{P}$, et al. Who is not adhering to physical activity referrals, and why? Scand J Prim Health Care 2011;29:234-40.

22. James DV, Johnston LH, Crone D, et al. Factors associated with physical activity referral uptake and participation. J Sports Sci 2008;26:217-24.

23. Schmidt M, Absalah S, Nierkens V, et al. Which factors engage women in deprived neighbourhoods to participate in exercise referral schemes? BMC Public Health 2008;8:371.

24. Kallings L. Physical activity on prescription: Studies on physical activity level, adherence and cardiovascular risk factors. Stockholm. Institutionen för neurobiologi, vårdvetenskap och samhälle/ Department of Neurobiology, Care Sciences and Society; 2008 Aug 15.

25. Pavey T, Taylor A, Fox K, et al. Effect of exercise referral schemes in primary care on physical activity and improving health outcomes: systematic review and meta-analysis. BMJ 2011;343:d6462.

26. Edwards RT, Linck $P$, Hounsome N, et al. Cost-effectiveness of a national exercise referral programme for primary care patients in Wales: results of a randomised controlled trial. BMC Public Health 2013;13:1021.

27. Romé Å, Persson U, Ekdahl C, et al. Willingness to pay for health improvements of physical activity on prescription. Scand J Public Health 2010;38:151-9. 
28. Jolly K, Duda JL, Daley A, et al. Evaluation of a standard provision versus an autonomy promotive exercise referral programme: rationale and study design. BMC Public Health 2009;9:176.

29. Sharma $\mathrm{H}$, Bulley $\mathrm{C}$, van Wijck FM. Experiences of an exercise referral scheme from the perspective of people with chronic stroke: a qualitative study. Physiotherapy 2012;98:336-43.

30. Isaacs AJ, Critchley JA, Tai SS, et al. Exercise Evaluation Randomised Trial (EXERT): a randomised trial comparing GP referral for leisure centre-based exercise, community-based walking and advice only. Health Technol Assess 2007;11:1-165, iii-iv.

31. Field AP, Gillett R. How to do a meta-analysis. Br J Math Stat Psychol 2010;63:665-94.

32. Tobi P, Estacio EV, Yu G, et al. Who stays, who drops out? Biosocial predictors of longer-term adherence in participants attending an exercise referral scheme in the UK. BMC Public Health 2012;12:347.

33. Leijon ME, Bendtsen $\mathrm{P}$, Nilsen $\mathrm{P}$, et al. Physical activity referrals in Swedish primary health care-prescriber and patient characteristics, reasons for prescriptions, and prescribed activities. BMC Health Serv Res 2008;8:201.

34. Sørensen JB, Kragstrup J, Skovgaard T, et al. Exercise on prescription: a randomized study on the effect of counseling vs counseling and supervised exercise. Scand J Med Sci Sports 2008;18:288-97.

35. Liberati A, Tetzlaff J, Altman D. G, \& PRISMA Group. (2010) Preferred reporting items for systematic reviews and meta-analyses: the PRISMA statement. Int J Surg 8:336-41.

36. Edmunds J, Ntoumanis N, Duda JL. Adherence and well-being in overweight and obese patients referred to an exercise on prescription scheme: a self-determination theory perspective. Psychol Sport Exerc 2007;8:722-40.

37. Tuller D. Renewed prescriptions for an old remedy: physical activity. Health Aff (Millwood) 2015;34:1440-3.

38. Lobelo F, Stoutenberg M, Hutber A. The exercise is medicine global health initiative: a 2014 update. Br J Sports Med 2014;48: 1627-33.

39. Coombes JS, Law J, Lancashire B, et al. "Exercise is medicine" curbing the burden of chronic disease and physical inactivity. Asia Pac J Public Health 2015;27:NP600-5.

40. Thompson PD. Exercise prescription and proscription for patients with coronary artery disease. Circulation 2005;112:2354-63.

41. Frémont $P$, Fortier M, Frankovich RJ. Exercise prescription and referral tool to facilitate brief advice to adults in primary care. Can Fam Physician 2014;60:1120-2, e591-2.

42. Seth $A$. Exercise prescription: what does it mean for primary care? Br J Gen Pract 2014;64:12-13.

43. Khan KM, Weller R, Blair SN. Prescribing exercise in primary care. BMJ 2011;343:d4141.

44. Pearce PZ. Exercise is medicine. Curr Sports Med Rep 2008;7:171-5

45. Sørensen JB, Skovgaard T, Puggaard L. Exercise on prescription in general practice: a systematic review. Scand J Prim Health Care 2006;24:69-74.

46. Morgan O. Approaches to increase physical activity: reviewing the evidence for exercise-referral schemes. Public Health 2005;119:361-70.

47. Stenman E, Leijon ME, Calling S, et al. Study protocol: a multi-professional team intervention of physical activity referrals in primary care patients with cardiovascular risk factors-the Dalby lifestyle intervention cohort (DALICO) study. BMC Health Serv Res 2012;12:173.

48. Hosper K, Deutekom M, Stronks K. The effectiveness of "exercise on prescription" in stimulating physical activity among women in ethnic minority groups in the Netherlands: protocol for a randomized controlled trial. BMC Public Health 2008:8:406.

49. Gallegos-Carrillo K, García-Peña C, Salmerón J, et al. Exercise-referral scheme to promote physical activity among hypertensive patients: design of a cluster randomized trial in the Primary Health Care Units of Mexico's Social Security System. BMC Public Health 2014:14:706.

50. Campbell F, Holmes M, Everson-Hock E, et al. A systematic review and economic evaluation of exercise referral schemes in primary care: a short report. Health Technol Assess 2015;19.

51. Tobi P, Estacio E, Seesaghur A, et al. Evaluation of Healthwise exercise referral scheme (final report). Prepared for Greenwich Teaching Primary Care Trust and Greenwich Leisure Limited. Institute for Health and Human Development, University of East London, 2009.

52. Patel A, Kolt G, Keogh J, et al. The Green Prescription and older adults: what do general practitioners see as barriers? J Prim Health Care 2012:4:320-7.
53. Patel A, Schofield GM, Kolt GS, et al. General practitioners' views and experiences of counselling for physical activity through the New Zealand Green Prescription program. BMC Fam Pract 2011;12:119.

54. Aittasalo M, Miilunpalo $\mathrm{S}$, Ståhl $\mathrm{T}$, et al. From innovation to practice: initiation, implementation and evaluation of a physician-based physical activity promotion programme in Finland. Health Promot Int 2007:22:19-27.

55. Melillo KD, Houde SC, Williamson E, et al. Perceptions of nurse practitioners regarding their role in physical activity and exercise prescription for older adults. Clin Excell Nurse Pract 2000;4:108-16.

56. Burns KJ, Camaione DN, Chatterton CT. Prescription of physical activity by adult nurse practitioners: a national survey. Nurs Outlook 2000;48:28-33.

57. Bohman DM, Mattsson L, Borglin G. Primary healthcare nurses' experiences of physical activity referrals: an interview study. Prim Health Care Res Dev 2015;16:270-80.

58. Persson G, Brorsson A, Ekvall Hansson E, et al. Physical activity on prescription (PAP) from the general practitioner's perspective-a qualitative study. BMC Fam Pract 2013;14:1

59. Dauenhauer JA, Podgorski CA, Karuza J. Prescribing exercise for older adults: a needs assessment comparing primary care physicians, nurse practitioners, and physician assistants. Gerontol Geriatr Educ 2006;26:81-99.

60. Tava'e N, Nosa V. The Green Prescription programme and the experiences of Pacific women in Auckland. J Prim Health Care 2012;4:313-19.

61. Sinclair KM, Hamlin MJ. Self-reported health benefits in patients recruited into New Zealand's Green Prescription' primary health care program. Southeast Asian J Trop Med Public Health 2007;38:1158-67.

62. Anokye NK, Trueman P, Green C, et al. The cost-effectiveness of exercise referral schemes. BMC Public Health 2011;11:954.

63. Elley CR, Garrett S, Rose SB, et al. Cost-effectiveness of exercise on prescription with telephone support among women in general practice over 2 years. Br J Sports Med 2011;45:1223-9.

64. Wiles R, Demain S, Robison J, et al. Exercise on prescription schemes for stroke patients post-discharge from physiotherapy. Disabil Rehabil 2008;30:1966-75.

65. Knight E, Stuckey MI, Petrella RJ. Health promotion through primary care: enhancing self-management with activity prescription and mHealth. Phys Sportsmed 2014;42:90-9.

66. Grandes G, Sanchez A, Montoya I, et al. Two-year longitudinal analysis of a cluster randomized trial of physical activity promotion by general practitioners. PLoS One 2011;6:e18363.

67. Galaviz K, Lévesque L, Kotecha J. Evaluating the effectiveness of a physical activity referral scheme among women. J Prim Care Community Health 2013;4:167-71.

68. Grandes G, Sanchez A, Sanchez-Pinilla RO, et al. Effectiveness of physical activity advice and prescription by physicians in routine primary care: a cluster randomized trial. Arch Intern Med 2009;169:694-701.

69. Shepich J, Slowiak JM, Keniston A. Do subsidization and monitoring enhance adherence to prescribed exercise? Am J Health Promot 2007;22:2-5.

70. Dinan S, Lenihan P, Tenn T, et al. Is the promotion of physical activity in vulnerable older people feasible and effective in general practice? Br J Gen Pract 2006;56:791-3.

71. Harrison RA, McNair F, Dugdill L. Access to exercise referral schemes-a population based analysis. J Public Health (Oxf) 2005;27:326-30.

72. Harrison RA, Roberts C, Elton PJ. Does primary care referral to an exercise programme increase physical activity one year later? A randomized controlled trial. J Public Health 2005;27:25-32.

73. Livingston PM, Craike MJ, Salmon J, et al. Effects of a clinician referral and exercise program for men who have completed active treatment for prostate cancer: a multicenter cluster randomized controlled trial (ENGAGE). Cancer 2015;121:2646-54.

74. Kallings LV, Leijon ME, Kowalski J, et al. Self-reported adherence: a method for evaluating prescribed physical activity in primary health care patients. J Phys Act Health 2009;6:483.

75. Taylor AH, Fox KR. Effectiveness of a primary care exercise referral intervention for changing physical self-perceptions over 9 months. Health Psychol 2005;24:11

76. Ackermann RT, Deyo RA, LoGerfo JP. Prompting primary providers to increase community exercise referrals for older adults: a randomized trial. J Am Geriatr Soc 2005;53:283-9.

77. Hawkins JL, Oliver EJ, Wyatt-Williams J, et al. Assessing the feasibility of using uniaxial accelerometers with an online support platform in the delivery of a community-based exercise referral scheme. J Prim Care Community Health 2014;5:288-90. 
78. Roessler KK, Ibsen B. Promoting exercise on prescription: recruitment, motivation, barriers and adherence in a Danish community intervention study to reduce type 2 diabetes, dyslipidemia and hypertension. J Public Health 2009;17:187-93.

79. Lamb SE, Bartlett HP, Ashley A, et al. Can lay-led walking programmes increase physical activity in middle aged adults? A randomised controlled trial. J Epidemiol Community Health 2002;56:246-52.

80. Kallings LV, Sierra Johnson J, Fisher RM, et al. Beneficial effects of individualized physical activity on prescription on body composition and cardiometabolic risk factors: results from a randomized controlled trial. Eur J Cardiovasc Prev Rehabil 2009;16:80-4.

81. Thomas $\mathrm{BH}$, Ciliska $\mathrm{D}$, Dobbins $\mathrm{M}$, et al. A process for systematically reviewing the literature: providing the research evidence for public health nursing interventions. Worldviews Evid Based Nurs 2004;1:176-84.

82. Smith WC, Anderson E, Salinas D, et al. A meta-analysis of education effects on chronic disease: the causal dynamics of the Population Education Transition Curve. Soc Sci Med 2015;127:29-40.
83. Orrow G, Kinmonth A-L, Sanderson S, et al. Effectiveness of physical activity promotion based in primary care: systematic review and meta-analysis of randomised controlled trials. BMJ 2012;344: e1389.

84. Egger M, Smith GD, Schneider M, et al. Bias in meta-analysis detected by a simple, graphical test. BMJ 1997;315:629-34.

85. Stathi A, McKenna J, Fox KR. The experiences of older people participating in exercise referral schemes. $J R$ Soc Promot Health 2004;124:18-23.

86. Pavey T, Taylor A, Hillsdon M, et al. Levels and predictors of exercise referral scheme uptake and adherence: a systematic review. J Epidemiol Commun Health 2012;66:737-44.

87. Jones $\mathrm{F}$, Harris $\mathrm{P}$, Waller $\mathrm{H}$, et al. Adherence to an exercise prescription scheme: the role of expectations, self-efficacy, stage of change and psychological well-being. $\mathrm{Br} J$ Health Psychol 2005;10:359-78.

88. Norman A, Bellocco R, Bergström A, et al. Validity and reproducibility of self-reported total physical activity-differences by relative weight. Int J Obes Relat Metab Disord 2001;25. 